\title{
Multitechnique Investigation of the Physisorption and Thermal Treatment of Mixed-Metal Clusters on Carbon
}

\author{
Christopher Willocq, ${ }^{\dagger}$ Arnaud Delcorte, ${ }^{\ddagger}$ Sophie Hermans, ${ }^{\dagger}$ Patrick Bertrand, ${ }^{*, \star}$ and \\ Michel Devillers*, ${ }^{*}$ \\ Unité de Chimie des Matériaux Inorganiques et Organiques, Université Catholique de Louvain, Place Louis \\ Pasteur 1/3, B-1348 Louvain-la-Neuve, Belgium, and Unité de Physico-Chimie et de Physique des Matériaux, \\ Université Catholique de Louvain, Place Croix du Sud 1, B-1348 Louvain-la-Neuve, Belgium
}

Received: February 1, 2005; In Final Form: March 14, 2005

\begin{abstract}
The three clusters $\left[\mathrm{Ru}_{6} \mathrm{PtC}(\mathrm{CO})_{16}(\mathrm{COD})\right](\mathbf{1}),\left[\mathrm{Ru}_{5} \mathrm{PtC}(\mathrm{CO})_{14}(\mathrm{COD})\right](\mathbf{2})(\mathrm{COD}=1,5$-cyclooctadiene), and $\left(\mathrm{NEt}_{4}\right)_{2}\left[\mathrm{Pd}_{6} \mathrm{Ru}_{6}(\mathrm{CO})_{24}\right](3)$ were physisorbed onto an active carbon support and used as molecular precursors for supported particles. The samples before and after thermal treatment at $300{ }^{\circ} \mathrm{C}$ were characterized by a combination of SIMS, XPS, SEM and XRD. It was found that the clusters are molecularly intact, but present in the form of agglomerates on the support at the end of the physisorption step. After thermal treatment, the ligands were lost in all cases, leaving on the surface bimetallic particles containing both starting metals $(\mathrm{Ru}-$ $\mathrm{Pt}$ in the case of $\mathbf{1}$ and $\mathbf{2}$, and $\mathrm{Ru}-\mathrm{Pd}$ in the case of $\mathbf{3}$ ). The presence of the counterion was evidenced for $\mathbf{3}$, before, but not after, heating. Molecular clusters are thus interesting precursors for the preparation of supported bimetallic phases, and SIMS is the ideal technique to characterize them at each step of their preparation.
\end{abstract}

\section{Introduction}

Metal clusters are fascinating molecules, comprising a core of metal atoms surrounded by organic ligands and whose properties can be tuned by subtle changes in their structures. For example, a right choice of ligands can shift their solubility from organic solvents to water. ${ }^{1}$ The number of metal atoms in the core can be varied between 3 to several hundreds (see, for example, the "giant" palladium clusters described by Moiseev et al. ${ }^{2}$ ), making them true intermediates between coordination compounds and colloids. Because of their size in the nanometer scale, they are ideal candidates for a variety of applications where size matters. In molecular electronics for example, they can be considered as quantum dots, as they contain a conducting core surrounded by an insulating layer. Building structures in 1- (polymers), 2- (sheets), or 3-dimensions (networks), through bridging ligands, ${ }^{3}$ could lead to useful devices. Another important application is catalysis, where clusters can be used not only as homogeneous or heterogeneous catalysts ${ }^{4-9}$ but also as "models" for metallic surfaces by virtue of the "clustersurface" analogy..$^{10}$ This analogy relies on the fact that a cluster core can be considered as a small piece of bulk metal. By studying the ligands arrangements, transformations, and bonding modes, one can gain information on the chemisorption or reactivity of small molecules on metal surfaces. In the field of heterogeneous catalysis, clusters need first to be deposited on a solid support and can then be used either as such or as molecular precursors. In the first case, they are usually called "immobilized" clusters, ${ }^{11}$ as the active species might resemble the intact cluster in the homogeneous phase. In the second case, the ligands are removed during an activation step to leave "naked" nanoparticles on the support. ${ }^{8}$ This latter strategy has

* To whom correspondence should be sent. M.D.: fax, +32-10-47 23 30; e-mail, devillers@ chim.ucl.ac.be. P.B.: fax, +32-10-47 34 52; e-mail: bertrand@pcpm.ucl.ac.be

† Unité de Chimie des Matériaux Inorganiques et Organiques.

† Unité de Physico-Chimie et de Physique des Matériaux. been shown to be highly successful for the preparation of active and selective catalysts for a variety of applications. ${ }^{8}, 12-14$ However, the structure of the active site arising from the supported cluster precursor has seldom been described in great detail. Mixed-metal clusters have an additional interest when compared to their homometallic counterparts. Indeed, the presence of two (or more) metals of different natures in their core can lead to beneficial effects from their synthesis (breakdown of symmetry leading to easier spectroscopic characterization) to their use (e.g., synergy in catalytic applications). ${ }^{15}$

Several authors have studied the fate of molecular clusters on surfaces, or their interactions with various supports. However, this has mainly been done by infrared spectroscopy and with the inorganic oxides used commonly as supports in heterogeneous catalysis (silica, alumina, etc.). ${ }^{11}$ There is very little information on the interaction of clusters with carbon substrates. ${ }^{11,16-21}$ This is probably due to the difficulty in characterizing them, as IR and Raman spectroscopies become hindered by absorption. There are also very few studies that give real molecular information on the immobilized species, after deposition on the support and/or activation. However, carbon supports are important for demanding processes, where the temperature, pressure and/or humidity level are high, and also for applications (such as electrochemical devices) that require conducting materials. For instance, the electrodes in fuel cells are composed of noble metal particles (preferably bimetallic) of nanometric size immobilized in a carbonaceous matrix that needs to be robust, conducting and with a high surface area. ${ }^{22,23}$ In addition, gaining molecular information on such kind of materials, at each step of their preparation and conditioning, is of primary importance. Indeed, the active sites are constituted by the local structure that can function effectively in the required transformation (typically, in heterogeneous catalysis, the adsorption/ transformation site for the incoming reactant molecules). An averaged "bulk" picture of such material, given by the classical characterization methods is thus not sufficient. In this context, 
a technique that has been rarely used, but which is capable of providing such molecular information, is secondary ion mass spectrometry (SIMS). ${ }^{24,25}$ Pure (unsupported) clusters have been characterized by mass spectrometry in the past mainly to identify new compounds and corroborate X-ray diffraction studies. ${ }^{26}$ Dynamic phenomena in the gas phase within the analysis chamber were identified (mainly in the case of laser desorption ionization, LDI), which is not the case in static SIMS. ${ }^{27}$ Studies involving molecular clusters and SIMS remain very scarce, being in the pure form (for example, for a $\mathrm{Ni}_{6}$ compound ${ }^{28}$ ) or supported $\left(\left[\mathrm{Ru}_{3}(\mathrm{CO})_{12}\right]\right.$ on zeolite $\mathrm{NaY}$ for instance $\left.{ }^{29}\right)$.

This paper aims at characterizing in details by SIMS, in combination with more "classical" methods (i.e., SEM, XPS, $\mathrm{XRD}$ ), the behavior of mixed-metal clusters deposited on a carbon support. They have been submitted in a subsequent step to a thermal treatment that would mimic for example the activation of a heterogeneous catalyst, or the conditioning of a fuel cell electrode. Here, we describe the fate of three representative bimetallic clusters, containing either palladium or platinum in addition to ruthenium in their cores. Three different metal clusters of variable nuclearity and composition were chosen, to study the influence of (i) the nature of the metal, (ii) the size of the cluster, and (iii) the presence of a counterion in the case of charged species. They have been physisorbed onto active carbon and then submitted to controlled heating under nitrogen flow to remove their ligands.

\section{Experimental Section}

All manipulations were carried out under oxygen-free nitrogen atmosphere using Schlenk techniques and all solvents were dried and distilled before use. Clusters and supported clusters were stored under $\mathrm{N}_{2}$.

2.1. Cluster Syntheses. The clusters $\left[\mathrm{Ru}_{6} \mathrm{PtC}(\mathrm{CO})_{16}(\mathrm{COD})\right]$ (1), $\left[\mathrm{Ru}_{5} \mathrm{PtC}(\mathrm{CO})_{14}(\mathrm{COD})\right](2)(\mathrm{COD}=1,5$-cyclooctadiene $)$, and $\left(\mathrm{NEt}_{4}\right)_{2}\left[\mathrm{Pd}_{6} \mathrm{Ru}_{6}(\mathrm{CO})_{24}\right](3)$ were prepared as described in the literature. ${ }^{30,31}$ The first two compounds were obtained by reacting, at room temperature, $\left[\mathrm{Pt}(\mathrm{COD}) \mathrm{Cl}_{2}\right]$ with either $(\mathrm{PPN})_{2^{-}}$ $\left[\mathrm{Ru}_{6} \mathrm{C}(\mathrm{CO})_{16}\right]$ or $(\mathrm{PPN})_{2}\left[\mathrm{Ru}_{5} \mathrm{C}(\mathrm{CO})_{14}\right]$, in the presence of a chlorine scavenger. They were then purified by chromatography on silica. The third species was synthesized by reduction of $\left[\mathrm{Ru}_{3}(\mathrm{CO})_{12}\right]$ with $\mathrm{NaBH}_{4}$, followed by redox condensation with $\left[\mathrm{Pd}(\mathrm{NCPh})_{2} \mathrm{Cl}_{2}\right]$ at $-50{ }^{\circ} \mathrm{C}$. The $\mathrm{Pd}_{6} \mathrm{Ru}_{6}$ cluster was precipitated by addition of $\left(\mathrm{NEt}_{4}\right) \mathrm{Br}$ and 2-propanol. Compounds $\mathbf{1 - 3}$ were obtained in $44 \%, 96 \%$, and $30 \%$ yield, respectively.

Note: in this paper, the term "cluster" has been used solely in the sense of molecular species containing metal-metal bonds, as defined by Cotton. ${ }^{40}$ When referring to dimers, trimers, etc. the words "aggregates" or "agglomerates" have been used instead, to avoid confusion (i.e., by avoiding expressions such as "clusters of clusters" or similar).

2.2. Physisorption. The support chosen was an active carbon (type $\mathrm{SX}+$ ) from Norit. It was sieved to keep only the particles comprised between 50 and $100 \mu \mathrm{m}$, and it has a specific surface area of $\sim 900 \mathrm{~m}^{2} / \mathrm{g}$.

The clusters $\mathbf{1}-\mathbf{3}$ were adsorbed onto this carbon support as follows:

The cluster $\left[\mathrm{Ru}_{6} \mathrm{PtC}(\mathrm{CO})_{16}(\mathrm{COD})\right](\mathbf{1})(34.2 \mathrm{mg})$ was placed with carbon $(180 \mathrm{mg})$ in a $100 \mathrm{~mL}$ Schlenk flask under nitrogen. Then $45 \mathrm{~mL}$ of 2-propanol and $5 \mathrm{~mL}$ of dichloromethane were added and the mixture was stirred at room temperature for 4 days in the dark. Finally, the solvents were removed under reduced pressure and the resulting black powder dried at room temperature. The same procedure was used for $\mathbf{2}$ and $\mathbf{3}$. The cluster $\left[\mathrm{Ru}_{5} \mathrm{PtC}(\mathrm{CO})_{14}(\mathrm{COD})\right](\mathbf{2})(34.6 \mathrm{mg})$ was adsorbed onto
$180 \mathrm{mg}$ of carbon, from a suspension in $45 \mathrm{~mL}$ of 2-propanol and $5 \mathrm{~mL}$ of dichloromethane. The cluster $\left(\mathrm{NEt}_{4}\right)_{2}\left[\mathrm{Pd}_{6} \mathrm{Ru}_{6^{-}}\right.$ $(\mathrm{CO})_{24}$ ] (3) (52.5 mg) was adsorbed onto $270 \mathrm{mg}$ of carbon from a slurry in $45 \mathrm{~mL}$ of 2-propanol and $5 \mathrm{~mL}$ of THF. Given that the solids were not recuperated by filtration at the end of the physisorption step, but that the solvents were merely removed by evaporation, it can be assumed that the clusters are present quantitatively in the obtained samples.

2.3. Thermal Treatment. The supported clusters were submitted to a thermal treatment in a tubular oven STF 16/450 from CARBOLITE. The samples were placed into porcelain combustion boats and heated at $300{ }^{\circ} \mathrm{C}$ for $1 \mathrm{~h}$ (heating ramp: $100{ }^{\circ} \mathrm{C}$ per hour) under a nitrogen stream.

2.4. Physicochemical Methods of Characterization. Infrared spectra of the three clusters were recorded in dichloromethane solution unless otherwise stated, on a BIO-RAD FTS 135 FTIR spectrometer.

The TGA (thermogravimetric) analyses of the three clusters were recorded on a TGA/DSC SDT 851 instrument from METTLER TOLEDO. These analyses were carried out with a heating ramp of $10^{\circ} \mathrm{C}$ per minute and under a nitrogen flow of $100 \mathrm{~mL} / \mathrm{min}$.

The ToF-SIMS analyses were performed in a PHI-EVANS time-of-flight SIMS (TRIFT 1) using a $15 \mathrm{keV} \mathrm{Ga}^{+}$beam (FEI 83-2 liquid metal ion source; $~ 550$ pA DC current; 22 ns pulse width bunched down to $\sim 1 \mathrm{~ns} ; 5 \mathrm{kHz}$ repetition rate for the mass range $0-5 \mathrm{kDa}){ }^{32}$ The experimental setup has been described in detail elsewhere. ${ }^{33}$ The secondary ion mass spectra were obtained by collecting the secondary ion signal in the mass range $0<m / z<5000$ for the 600 s bombardment of a $173 \times$ $173 \mu \mathrm{m}^{2}$ sample area, which corresponds to a fluence of $3.5 \times$ $10^{11}$ ions $/ \mathrm{cm}^{2}$, well in the static regime. To improve the measured intensities, the secondary ions were post-accelerated by a high voltage $(7 \mathrm{kV})$ in front of the detector. For these analyses, all the samples were pressed and analyzed on an indium support.

The SEM (scanning electron microscopy) images and EDXS (energy-dispersive X-ray spectroscopy) spectra were acquired on a FEG digital scanning microscope (DSM 982 Gemini from LEO) equipped with a EDXS detector (Phoenix CDU LEAP). The samples were fixed by double-sided conducting adhesive tape onto $5 \mathrm{~mm}$ diameter aluminum specimen stubs from Agar Scientific.

The X-ray diffraction (XRD) analyses were recorded for the supported clusters on a SIEMENS D5000 diffractometer equipped with a copper source $\left(\lambda_{\mathrm{K} \alpha}=154.18 \mathrm{pm}\right)$. The samples were placed on quartz monocrystals and the crystalline phases were identified by reference to the JCPDS database.

The XPS (X-ray photoelectron spectroscopy) measurements were carried out at room temperature on a SSI-X-probe (SSX100/206) photoelectron spectrometer from Surface Science Instruments (USA) equipped with a monochromatized microfocus Al X-ray source. Samples were stuck on small troughs with double-face adhesive tape and then placed on an insulating homemade ceramic carousel (Macor Switzerland). Charge effects were avoided by placing a nickel grid above the samples and using a flood gun set at $8 \mathrm{eV}$. The quantification was based on the C1s, N1s, Pd3d, Ru3d, and Pt4f photopeaks. The energy scale was calibrated with reference to the peak $A u 4 f_{7 / 2}$ at 84 $\mathrm{eV}$, and the binding energies were calculated with respect to the $C-(\mathrm{C}, \mathrm{H})$ component of the $\mathrm{C} 1 \mathrm{~s}$ peak fixed at $284.8 \mathrm{eV}$. Data treatment was performed with the CasaXPS program (Casa Software Ltd., U.K.). The peaks were decomposed into a sum of Gaussian/Lorentzian (85/15) after subtraction of a Shirley 
TABLE 1: Constraints Used for XPS Data Treatment

\begin{tabular}{|c|c|c|c|c|}
\hline \multicolumn{2}{|c|}{ peaks considered } & \multirow{2}{*}{$\begin{array}{l}\text { area } \\
\mathrm{A} / \mathrm{B}\end{array}$} & \multirow[b]{2}{*}{$\Delta(\mathrm{B}-\mathrm{A})(\mathrm{eV})$} & \multirow[b]{2}{*}{ fwhm ratio } \\
\hline A & $\mathrm{B}$ & & & \\
\hline $\mathrm{Pt} 4 \mathrm{f}_{7 / 2}$ & $\operatorname{Pt} 4 \mathrm{f}_{5 / 2}$ & 1.33 & 3.33 & 1 \\
\hline $\mathrm{Ru} 3 \mathrm{~d}_{5 / 2}$ & $\mathrm{Ru} 3 \mathrm{~d}_{3 / 2}$ & 1.5 & 4.17 & 1 \\
\hline $\mathrm{Pd} 3 \mathrm{~d}_{5 / 2}$ & $\operatorname{Pd} 3 d_{3 / 2}$ & 1.5 & 5.26 & 1 \\
\hline
\end{tabular}

TABLE 2: Results of Thermogravimetric Analysis for Clusters 1, 2, and 3 under Nitrogen

\begin{tabular}{cccl}
\hline cluster & $\begin{array}{c}\text { weight } \\
\text { loss }(\%)\end{array}$ & $\begin{array}{c}\text { final decomp } \\
\text { temp }\left({ }^{\circ} \mathrm{C}\right)^{a}\end{array}$ & \multicolumn{1}{c}{$\begin{array}{c}\text { calcd weight } \\
\text { loss }(\%)\end{array}$} \\
\hline$\left[\mathrm{Ru}_{6} \mathrm{PtC}(\mathrm{CO})_{16}(\mathrm{COD})\right](\mathbf{1})$ & 38.1 & 290 & $\begin{array}{l}40.6 \\
(=16 \mathrm{CO}+1 \mathrm{COD})\end{array}$ \\
& 38.3 & 300 & $\begin{array}{l}41 \\
(=14 \mathrm{CO}+1 \mathrm{COD})\end{array}$ \\
{$\left[\mathrm{Ru}_{5} \mathrm{PtC}(\mathrm{CO})_{14}(\mathrm{COD})\right](\mathbf{2})$} & 39.2 & 250 & $\begin{array}{l}42.8 \\
\left(=24 \mathrm{CO}+2 \mathrm{NEt}_{4}{ }^{+}\right)\end{array}$ \\
& & & $\left(\mathrm{NEt}_{4}\right)_{2}\left[\mathrm{Pd}_{6} \mathrm{Ru}_{6}(\mathrm{CO})_{24}\right](\mathbf{3})$ \\
& 390 & &
\end{tabular}

${ }^{a}$ The final decomposition temperature corresponds to the temperature at which the clusters have lost all their ligands.

TABLE 3: XPS Results for the Supported Clusters 1, 2, and 3 before and after Thermal Treatment

\begin{tabular}{clllllll}
\hline & & \multicolumn{2}{c}{$\begin{array}{c}\text { after adsorption } \\
\text { on } \mathrm{C}_{\mathrm{SX}+}\end{array}$} & & \multicolumn{2}{c}{$\begin{array}{c}\text { after heating } \\
\text { treatment }\end{array}$} \\
cluster & ratios & calcd $^{a}$ & exptl & & calcd $^{a}$ & exptl \\
\hline$\left[\mathrm{Ru}_{6} \mathrm{PtC}(\mathrm{CO})_{16}(\mathrm{COD})\right](\mathbf{1})$ & $\mathrm{Ru} / \mathrm{Pt}$ & 6 & 5.04 & & 6 & 5.62 \\
{$\left[\mathrm{Ru}_{5} \mathrm{PtC}(\mathrm{CO})_{14}(\mathrm{COD})\right](\mathbf{2})$} & $\mathrm{Ru} / \mathrm{Pt}$ & 5 & 4.81 & & 5 & 4.66 \\
$\left(\mathrm{NEt}_{4}\right)_{2}\left[\mathrm{Pd}_{6} \mathrm{Ru}_{6}(\mathrm{CO})_{24}\right](\mathbf{3})$ & $\mathrm{Ru} / \mathrm{Pd}$ & 1 & 0.95 & & 1 & 0.64 \\
& $\mathrm{~N} / \mathrm{C}$ & 0.002 & 0.012 & & 0 & 0.0035
\end{tabular}

\begin{abstract}
${ }^{a}$ The calculated values are bulk molar ratios. Before heating, the amount of $\mathrm{C}$ taken into consideration for the calculations corresponds to the sum arising from the carbon support, the carbonyl ligands and the central carbide atom (except for 3) of the clusters. After thermal treatment, the amount of $\mathrm{C}$ considered results from the carbon support and the central carbide atom (except for $\mathbf{3}$ ) of the clusters only.
\end{abstract}

type baseline. The constraints used are presented in Table 1. Given the superposition of the $\mathrm{C} 1 \mathrm{~s}$ and $\mathrm{Ru} 3 \mathrm{~d}_{3 / 2}$ peaks, these constraints were particularly important to quantify the ruthenium. The following method was used: a Gaussian/Lorentzian (85/ 15) was placed at the position of the $R u 3 d_{5 / 2}$ peak, which is visible on the right-hand side (lower binding energy) of the $\mathrm{C} 1 \mathrm{~s}$ peak. The contribution of the $\mathrm{Ru} 3 \mathrm{~d}_{3 / 2}$ peak to subtract from the carbon component was calculated by reference to the $R u 3 d_{5 / 2}$ peak by placing another Gaussian/Lorentzian (85/15) at 4.17 $\mathrm{eV}$ toward higher binding energy, and imposing an area ratio $R u 3 d_{5 / 2} / R u 3 d_{3 / 2}=1.5$ and a fwhm ratio of unity. Because of this problem of overlap, the experimental error on the Ru surface atomic concentration percentage is high, and therefore the $\mathrm{Ru} /$ $\mathrm{Pt}$ and $\mathrm{Ru} / \mathrm{Pd}$ ratios quoted in Table 3 have to be taken with caution.

\section{Results}

3.1. Preparations. The three synthesized clusters, $\left[\mathrm{Ru}_{6} \mathrm{PtC}\right.$ $\left.(\mathrm{CO})_{16}(\mathrm{COD})\right](\mathbf{1}),\left[\mathrm{Ru}_{5} \mathrm{PtC}(\mathrm{CO})_{14}(\mathrm{COD})\right](\mathbf{2})$ and $\left(\mathrm{NEt}_{4}\right)_{2}\left[\mathrm{Pd}_{6}-\right.$ $\mathrm{Ru}_{6}(\mathrm{CO})_{24}$ (3), were identified from their IR fingerprints. Indeed, they contain $\mathrm{CO}$ ligands that give characteristic peaks between 2200 and $1600 \mathrm{~cm}^{-1}$, corresponding to $\mathrm{C}-\mathrm{O}$ bond stretching. Because the molecular structures of these clusters have been determined by X-ray crystallography, ${ }^{30,31}$ their color and IR bands guarantee their unambiguous identification. The spectra recorded in this study gave carbonyl stretching peaks at the following values ( $\mathrm{s}=$ strong, $\mathrm{m}=$ medium, $\mathrm{w}=$ weak, sh $=$ shoulder, br = broad): $1 v_{\mathrm{CO}}\left(\mathrm{cm}^{-1}\right) 2078(\mathrm{~m}), 2035(\mathrm{~s})$, and $1998(\mathrm{~m}) ; 2 v_{\mathrm{CO}}\left(\mathrm{cm}^{-1}\right) 2077(\mathrm{~m}), 2050$ (s), 2033 (s), 2011 (s), 1989 (sh), 1966 (sh), and 1817 (w); $3 v_{\mathrm{CO}}\left(\mathrm{cm}^{-1}\right.$ in THF)
2020 (s), 2006 (sh), 1956 (w), 1858 (w), and 1823 (w). This fits perfectly with the literature data ${ }^{30,31}$ and confirms the success of the syntheses.

These clusters were then physically adsorbed onto the carbon support in a mixture of solvents. To wet the carbonaceous material, an alcoholic medium was necessary and 2-propanol was chosen. However, because the clusters were not soluble in 2-propanol, another organic solvent (in which each given cluster is soluble) was added (dichloromethane for $\mathbf{1}$ and $\mathbf{2}$, and THF for 3). After removal of the solvents, the three supported clusters were characterized by SIMS, XPS and SEM, then heated at 300 ${ }^{\circ} \mathrm{C}$ for $1 \mathrm{~h}$ under nitrogen. These heating conditions were determined from TGA analysis of the corresponding pure clusters, which showed that they lose all their ligands below $300{ }^{\circ} \mathrm{C}$ (see Table 2). After such a treatment, the supported clusters were assumed to be converted into "naked" supported metallic particles, bearing some relationship with the parent molecular clusters in terms of size, composition, etc. These supported particles were thus characterized by SIMS, XPS, SEM and $\mathrm{XRD}$, to assess the extent of this relationship.

3.2. $\left[\operatorname{Ru}_{\mathbf{6}} \mathbf{P t C}(\mathbf{C O})_{\mathbf{1 6}}(\mathbf{C O D})\right]$ (1). The positive and negative SIMS spectra for $\mathbf{1}$ supported on carbon are displayed in Figure $1 b-d$, and the reference spectrum for the pure, unsupported cluster is presented in Figure 1a. The high-mass region for the sample supported on carbon consists of several peaks, which are representative of the cluster, and similar to the reference spectrum. The molecular ion peak, which was not clearly observed for the pure cluster (Figure 1a), is present in both spectrum modes around $\mathrm{m} / \mathrm{z} 1370$ (Figure 1b,c). At lower masses, a series of regularly spaced peaks correspond to the successive losses of CO ligands, and also to the loss of the COD moiety. In the positive spectrum (Figure 1c), the metallic core of $1\left(\left[\mathrm{Ru}_{6} \mathrm{PtC}\right]^{+}\right)$is observed around $\mathrm{m} / z$ 813.5. Overall, the high mass region of the SIMS spectra is complex, the signal/ noise ratio is unusually low and the molecular peaks are significantly broadened. The explanation of these effects has been discussed in a preliminary report on the subject. ${ }^{34}$ First, the multiplicity of peaks surrounding the expected nominal mass of the intact cluster and its fragments obviously arises from the wide isotopic distribution of the core metal atoms, $\mathrm{Ru}$ and $\mathrm{Pt}$. The reason for the peak broadening and the intense background noise covering that part of the mass spectrum, however, is more subtle. Using an energy filter, it could be shown that these features are caused by metastable decay reactions occurring in the gas-phase and producing a population of daughter ions with a kinetic energy deficit. ${ }^{35}$ Despite these experimental artifacts, the observation of the parent ion leads to the important conclusion that the molecular structure of the cluster is intact on the support at the end of the physisorption step. In addition, when looking at the whole studied mass range (Figure 1d), one notices that the peak series described above is repeated a number of times toward higher $\mathrm{m} / \mathrm{z}$ ratios, indicating the presence of cluster aggregates, i.e., dimers, trimers, etc. of cluster cores surrounded by a layer of ligands. Such coalescence of the metallic cores can be explained by the fact that in intact molecular clusters in solution, the structures (and their fluxionality) can be rationalized by considering that the ligands form a external layer that can spin independently around the core (libration of the metal core inside the ligand sphere, identified within the ligand polyhedral model (LPM) theory). ${ }^{36}$ The XPS results for the supported cluster $\mathbf{1}$ before thermal treatment are displayed in Table 3. The calculated and experimental values for the $\mathrm{Ru} / \mathrm{Pt}$ ratio are relatively similar, indicating that the two 
a)

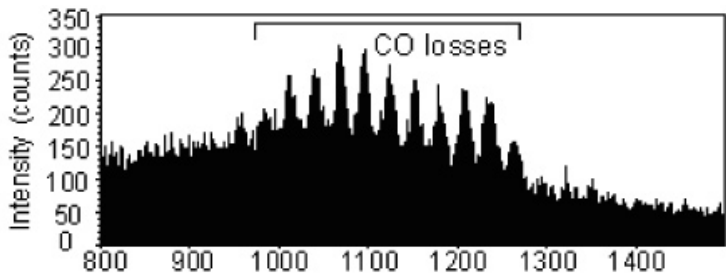

b)

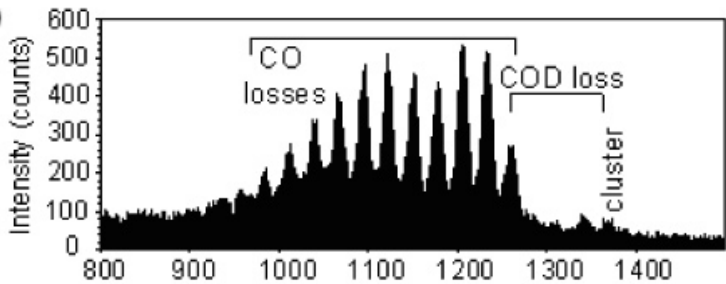

c)

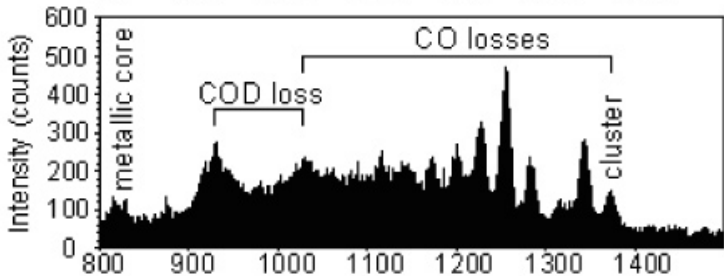

d)

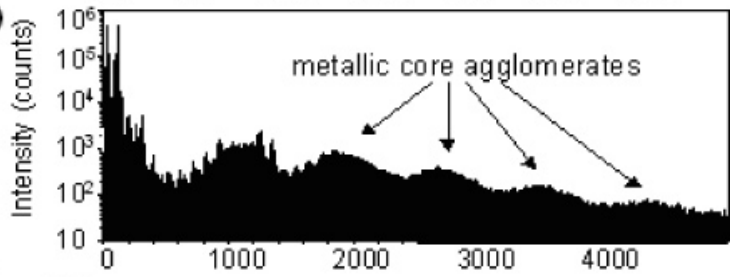

e)
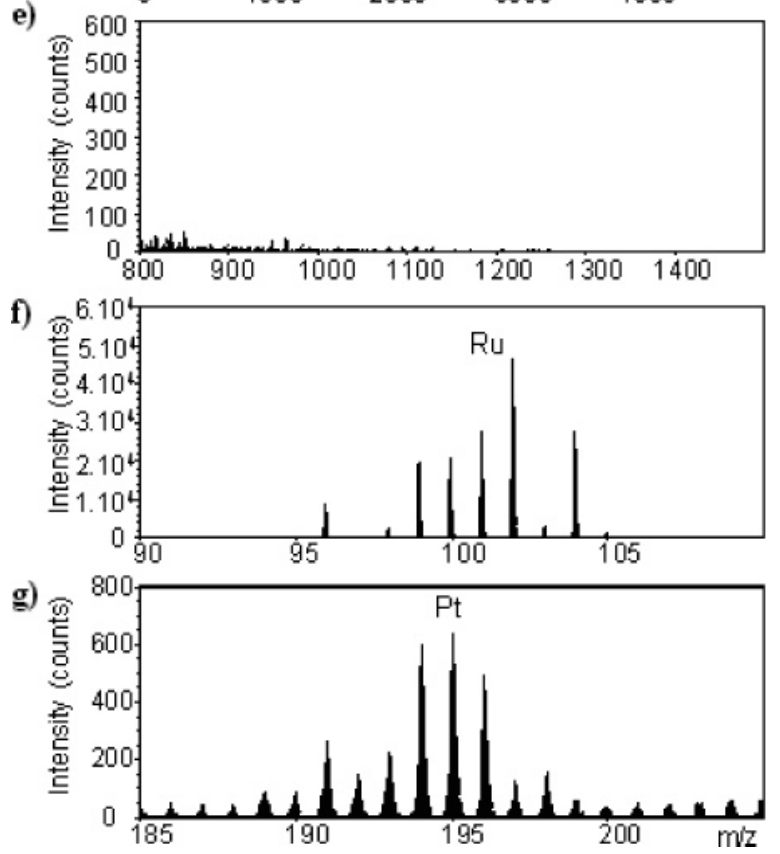

Figure 1. SIMS spectra of the cluster $\left[\mathrm{Ru}_{6} \mathrm{PtC}(\mathrm{CO})_{16}(\mathrm{COD})\right](\mathbf{1})$ supported on $\mathrm{C}_{\mathrm{SX}+}$ : (a) pure unsupported cluster as reference (negative spectrum), (b) negative spectrum before thermal treatment, (c) and (d) positive spectra before thermal treatment, (e) negative spectrum after thermal treatment, (f) and (g) positive spectra after thermal treatment.

metals are present on the surface, and that the composition of the starting cluster is essentially retained.

After heating the supported cluster at $300{ }^{\circ} \mathrm{C}$ for $1 \mathrm{~h}$, the SIMS spectra are drastically modified. The high-mass region (Figure 1e) does not show the presence of either the parent ion or its $\mathrm{CO}$-deficient fragments, suggesting that the ligands have been removed. Nevertheless, the low-mass region (Figure 1f,g) still displays distributions around $\mathrm{m} / \mathrm{z}, 101$ and $\mathrm{m} / \mathrm{z}, 195$ showing a)

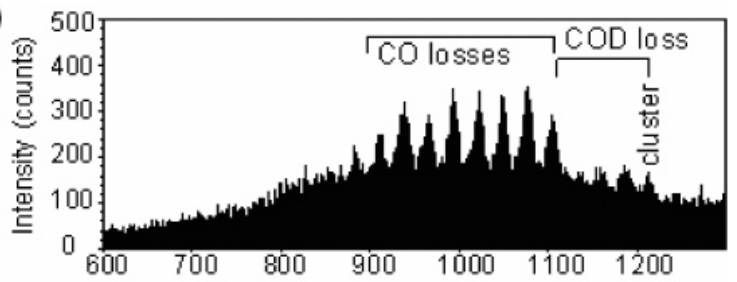

b)

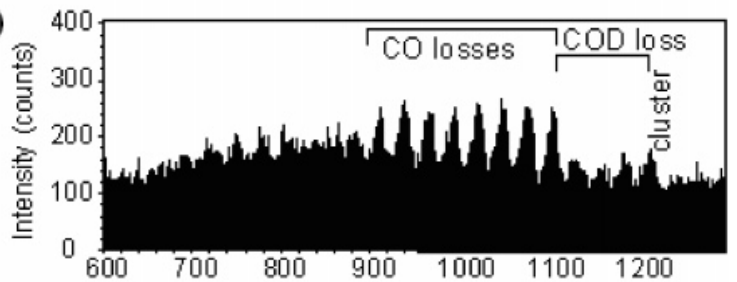

c)

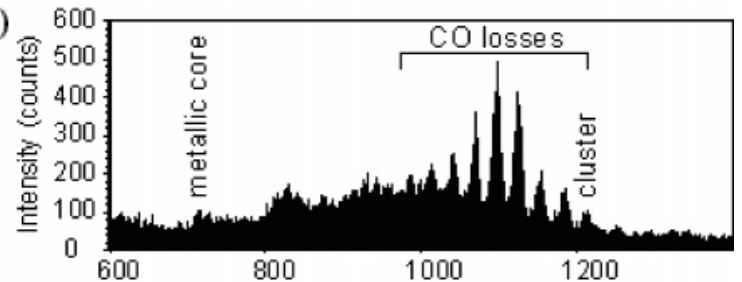

d)

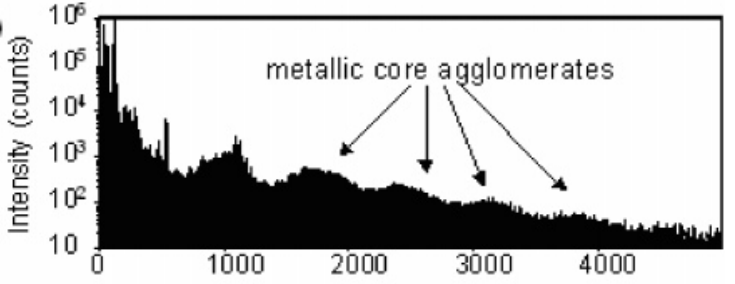

e)

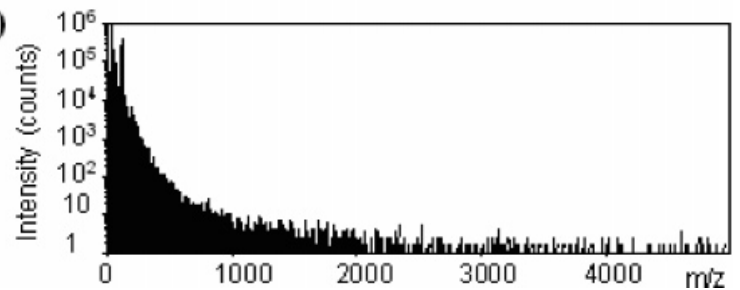

Figure 2. SIMS spectra of the cluster $\left[\mathrm{Ru}_{5} \mathrm{PtC}(\mathrm{CO})_{14}(\mathrm{COD})\right](2)$ supported on $\mathrm{C}_{\mathrm{SX}+}$ : (a) pure unsupported cluster as reference (negative spectrum), (b) negative spectrum before thermal treatment, (c) and (d) positive spectra before thermal treatment, and (e) positive spectrum after thermal treatment.

that ruthenium and platinum remain present on the support. The absence of any peak corresponding to the initial heterometallic core indicates that some reorganization occurs at the surface during the thermal treatment. The XPS results after heating are shown in Table 3: the $\mathrm{Ru} / \mathrm{Pt}$ ratio measured on the surface is again similar to the calculated value, i.e., to the $\mathrm{Ru} / \mathrm{Pt}$ ratio in the starting cluster. An interesting observation is that the $\mathrm{Ru}_{3 / 2}$ peak is slightly shifted toward lower binding energies, and that the Pt area, corresponding to a doublet of doublets (Pt metal + oxide) has become sharper. This indicates metal reduction during thermal treatment. The XRD pattern of the treated sample contains lines of weak intensity corresponding to metallic ruthenium and indicating the presence of small metal particles on the support.

3.3. $\left[\mathrm{Ru}_{\mathbf{5}} \mathrm{PtC}(\mathrm{CO})_{14}(\mathrm{COD})\right]$ (2). The SIMS spectra obtained for cluster 2 supported on carbon resemble those of cluster 1 and are presented in Figure 2. The molecular ion peak (at $\mathrm{m} / \mathrm{z}$ 1213) and the loss of CO ligands, as well as the metallic core (at $\mathrm{m} / \mathrm{z}, 712$ ), are all observed (Figure 2b,c). Very similar SIMS spectra were obtained for cluster $\mathbf{2}$ cast from solution on silicon wafers $^{34}$ (shown in Figure 2a), so it can be concluded that the 
a)

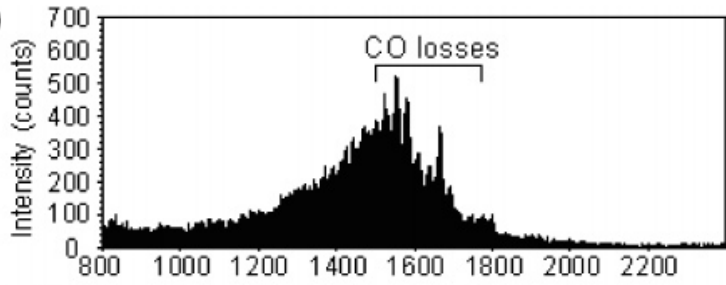

b)

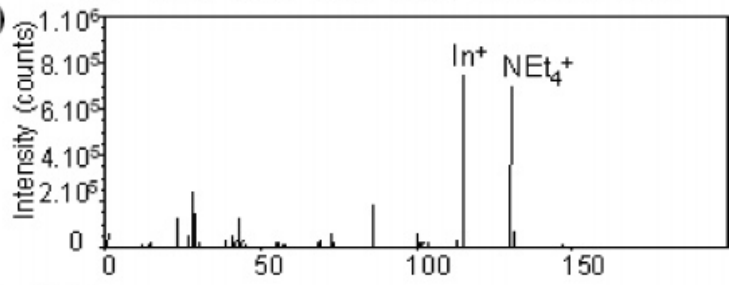

c)

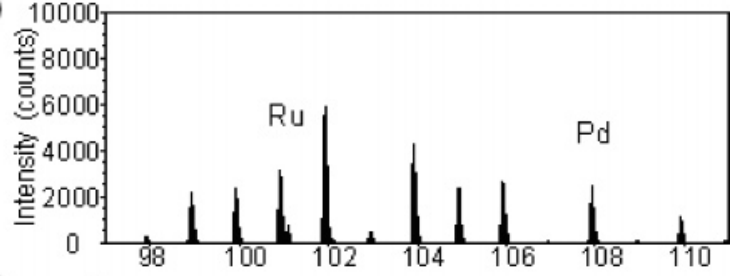

d)

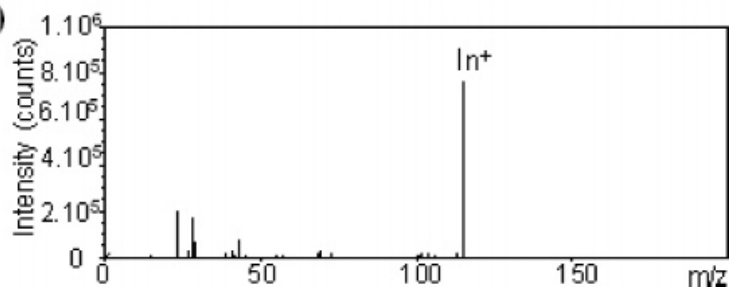

Figure 3. SIMS spectra of the cluster $\left(\mathrm{NEt}_{4}\right)_{2}\left[\mathrm{Pd}_{6} \mathrm{Ru}_{6}(\mathrm{CO})_{24}\right](\mathbf{3})$ supported on $\mathrm{C}_{\mathrm{SX}+}$ : (a) negative spectrum before thermal treatment, (b) positive spectrum before thermal treatment, (c) and (d) positive spectra after thermal treatment.

clusters are present on the support with their intact molecular structure. Again, a positive mass spectrum taken on the whole investigated mass range (Figure $2 \mathrm{~d}$ ) shows large distributions separated by a mass corresponding to the cluster core. This observation indicates the presence of cluster aggregates on the surface, involving two to five molecules. The XPS results (Table 3 ) before thermal treatment lead to the same conclusions as for cluster $\mathbf{1}$, as the $\mathrm{Ru} / \mathrm{Pt}$ ratio measured corresponds to that of the starting cluster.

After thermal treatment, the SIMS spectra are similar to those of cluster 1 (Figure 2e). The ligands are completely removed, the metallic core is not observed anymore, but the two metals are still present. The XPS results after heating (Table 3) again show that the composition of the starting cluster is preserved (the experimental $\mathrm{Ru} / \mathrm{Pt}$ ratio fit roughly the calculated value). Again, metal reduction is deduced from peaks shifts toward lower binding energies. The XRD pattern of the heated sample also displays weak lines assignable to metallic ruthenium.

3.4. $\left(\mathbf{N E t}_{4}\right)_{2}\left[\mathbf{P d}_{6} \mathbf{R u}_{6}(\mathbf{C O})_{24}\right]$ (3). The SIMS spectra of the supported cluster $\mathbf{3}$ are shown in Figure 3. The high-mass region of these spectra is more difficult to interpret than those of $\mathrm{Ru}-$ Pt clusters. This might be due to the higher nuclearity of $\mathbf{3}$. The negative spectrum (Figure $3 a$ ) consists of a broad distribution made up of several peaks corresponding to fragments arising from $\mathrm{CO}$ losses. The molecular ion and the metallic core, expected at masses of 1917 and 1245, respectively, are not observed. The positive spectrum also shows $\mathrm{CO}$ losses, and the presence of ruthenium and palladium. In addition, the low-mass region reveals the presence of the counterion $\left(\mathrm{NEt}_{4}{ }^{+}\right)$at $\mathrm{m} / \mathrm{z}$ 130 (Figure 3b), and $\mathrm{In}^{+}$arising from the sample holder.
Agglomerates at very high masses corresponding to several cluster cores are also observed. Once more, the agreement between experimental and calculated XPS data for the $\mathrm{Ru} / \mathrm{Pd}$ ratio (Table 3) indicates that the initial composition is conserved during the physisorption step. The agglomeration of clusters on the support is confirmed by SEM (Figure 4). The SEM images of cluster $\mathbf{3}$ after physisorption show the carbon support as a dark background (objects of varying shapes with flat faces), and the metallic phase as bright agglomerates of variable sizes (from a few nm to $1-2 \mu \mathrm{m}$ ) dispersed on the surface of the support (Figure 4a). The EDXS analysis of these metallic aggregates shows that they contain the same amount of ruthenium and palladium, as expected from the cluster formulation (Figure 4b). Therefore, we postulate that the clusters retain their molecular structure when they are physisorbed on the support, but that they form agglomerates to a certain extent.

After heating the supported cluster 3 at $300{ }^{\circ} \mathrm{C}$ for $1 \mathrm{~h}$, the negative SIMS spectra in the high-mass region (not shown) does not display any peak anymore, indicating that the CO ligands are removed. In the low-mass region of the positive spectrum, palladium and ruthenium are still present (Figure 3c). In addition to removing the ligands, the heating treatment also removes the counterions of the clusters (see in Figure 3d), to give a supported metallic phase. In this figure, $\mathrm{In}^{+}$from the support is also observed. After thermal treatment, the experimental ratio $\mathrm{Ru} /$ Pd observed by XPS (Table 3) seems to decrease. Moreover, the $R u 3 d_{5 / 2}$ peak is shifted from 282.4 to $281.6 \mathrm{eV}$, indicating reduction, whereas $\mathrm{Pd}$ was already in a reduced state in the starting cluster and is thus not affected by heating. XPS analysis also indicates that the amount of nitrogen decreases during thermal treatment, in agreement with the loss of counterion observed by SIMS. The SEM images after heating are very similar to those before heating, still showing agglomerates containing the same amount of $\mathrm{Ru}$ and $\mathrm{Pd}$ (Figure $4 \mathrm{c}-\mathrm{e}$ ). The XRD pattern of this sample displays lines that are intermediate between those of pure ruthenium and pure palladium, suggesting the presence of a bimetallic phase (Figure 5).

\section{Discussion}

When supported on carbon, the two $\mathrm{Ru}-\mathrm{Pt}$ clusters have a very similar response in SIMS, whereas the $\mathrm{Ru}-\mathrm{Pd}$ cluster gives a different kind of spectrum. For the $\mathrm{Ru}-\mathrm{Pt}$ clusters, the molecular ion, all ligands losses and the cluster core are observed, whereas for the $\mathrm{Ru}-\mathrm{Pd}$ cluster, only fragments are observed. This might be due to the higher nuclearity of the latter, or to an effect of the metal nature. More particularly, the molecular ion for cluster $\mathbf{3}$ is larger than that for $\mathbf{1}$ and $\mathbf{2}$ : clusters 1 and 2 contain respectively 7 and 6 metal atoms, whereas $\mathbf{3}$ contains 12. It is known that the risk of fragmentation increases with the size of the molecule. Moreover, Pd-containing clusters are usually more air-sensitive than Pt-based ones, indicating a lower chemical stability of this type of clusters. This lowered stability might hinder observation of the molecular ion in the SIMS spectrum, because it would lead to decomposition and/or increased fragmentation under analysis conditions (i.e., under impact of primary ions). Finally, the presence of a carbon matrix, apart from its obvious dilution effect, could also affect the quality of the results, but this effect would be the same for $\mathbf{1 - 3}$.

When considering the XPS results, one has to keep in mind that the depth of analysis is about $3-7 \mathrm{~nm},{ }^{37}$ and that the cluster sizes are about $1.5 \mathrm{~nm}$. This implies that if the clusters are really well dispersed on the surface, as a (sub)monolayer, the XPS analysis must correspond to a "bulk" analysis of the clusters. 
a)

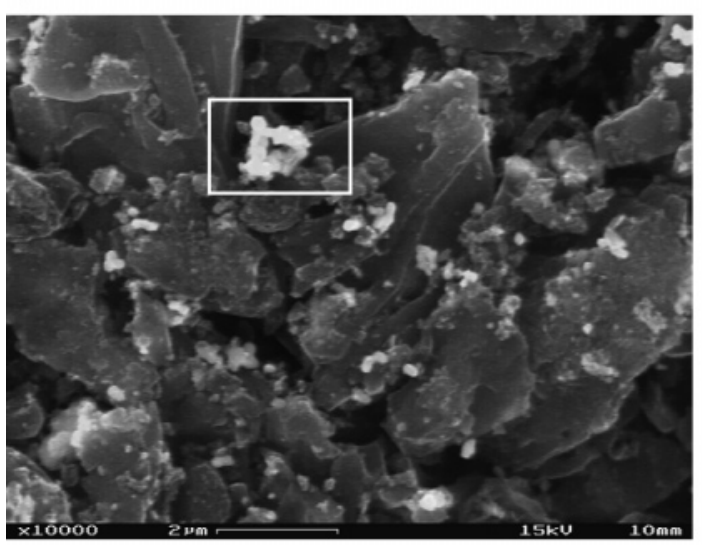

b)

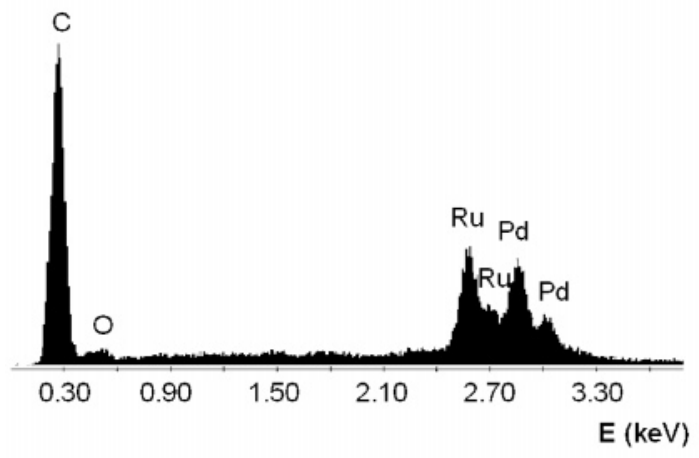

c)

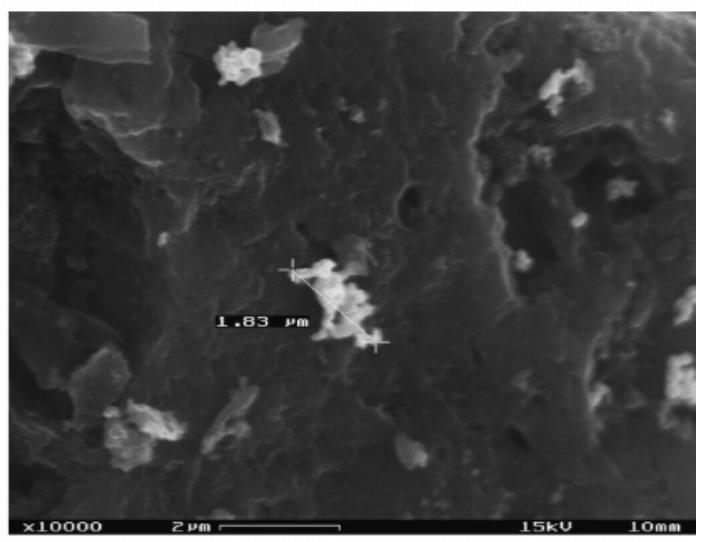

d)

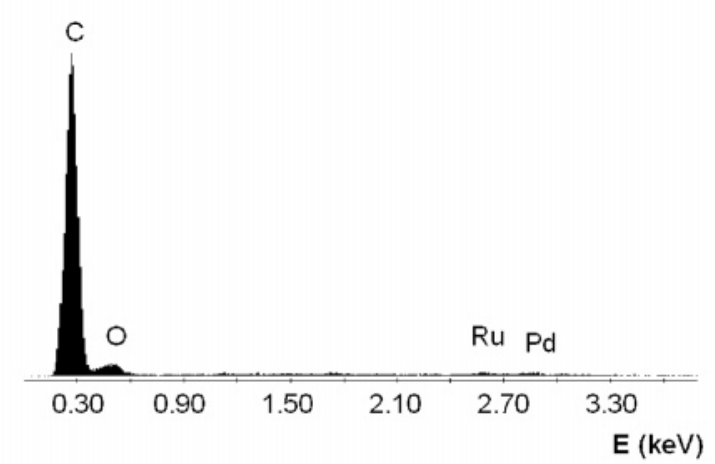

e)

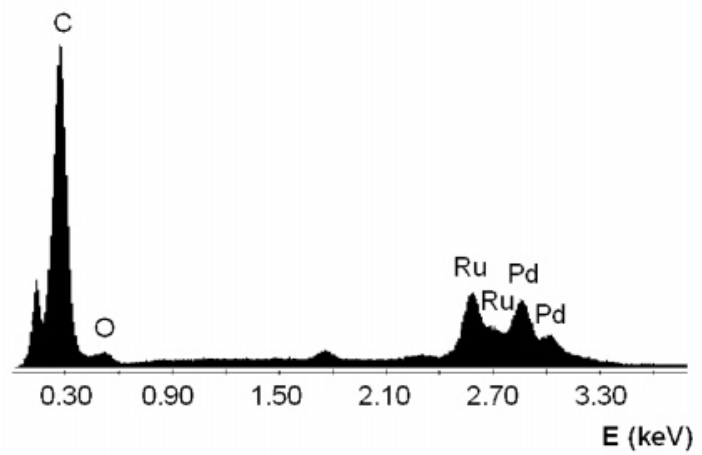

Figure 4. $\mathrm{SEM}$ images of the cluster $\left(\mathrm{NEt}_{4}\right)_{2}\left[\mathrm{Pd}_{6} \mathrm{Ru}_{6}(\mathrm{CO})_{24}\right]$ (3) supported on $\mathrm{C}_{\mathrm{SX}+}$ : (a) SEM image of the supported cluster 3 before thermal treatment, (b) EDXS spectrum of the zone marked by a white frame in (a), (c) SEM image of the supported cluster $\mathbf{3}$ after thermal treatment, (d) EDXS spectrum of the dark background in image (c), (e) EDXS spectrum of the bright feature $1.83 \mu \mathrm{m}$ in size in image (c).

This might explain why the $\mathrm{Ru} / \mathrm{Pt}$ or $\mathrm{Ru} / \mathrm{Pd}$ ratios measured experimentally are roughly similar to the values calculated on the basis of the cluster initial composition. However, the SEM and SIMS analyses have shown that the clusters are present on the surface as aggregates, whose sizes can be up to $1 \mu \mathrm{m}$. Because this is above the XPS detection depth, surface effects, such as metal segregation, could actually be observed. Metal segregation is usually driven by the respective surface free energies of the two metals. For example, for cluster 3, the Ru/ $\mathrm{Pd}$ ratio seems to decrease during heating, suggesting a palladium enrichment at the surface. Indeed, the value of surface free energy for palladium is smaller than for ruthenium, ${ }^{38}$ which could bring palladium to the surface and make ruthenium less accessible for XPS analysis. In the case of clusters $\mathbf{1}$ and $\mathbf{2}$, the $\mathrm{Ru} / \mathrm{Pt}$ ratios stay relatively constant, which might indicate that the two metals remain intimately mixed to a certain extent, during the whole preparation and heating procedure. However, as fragments corresponding to "naked" cluster cores are not observed anymore by SIMS after thermal treatment, the atomic structure of the particles formed is probably more complicated than a simple juxtaposition of unaltered cluster cores.

The results of XRD characterization could give partial information regarding the composition of the metallic phase formed after heating. Indeed, for $\mathbf{1}$ and $\mathbf{2}$, only metallic $\mathrm{Ru}$ is observed in the diffractograms. This implies that domains of a certain size containing only metallic ruthenium might exist in the sample. However, it does not exclude the presence of bimetallic phases containing a small portion of $\mathrm{Pt}$ atoms (as the $\mathrm{Ru} / \mathrm{Pt}$ metal ratios are 6/1 and 5/1) replacing $\mathrm{Ru}$ atoms in a phase whose structure corresponds to metallic $\mathrm{Ru}$. This is the prediction that can be made from the $\mathrm{Ru}-\mathrm{Pt}$ phase diagram, ${ }^{39}$ which shows that above 80 atomic percent ruthenium, the phase 


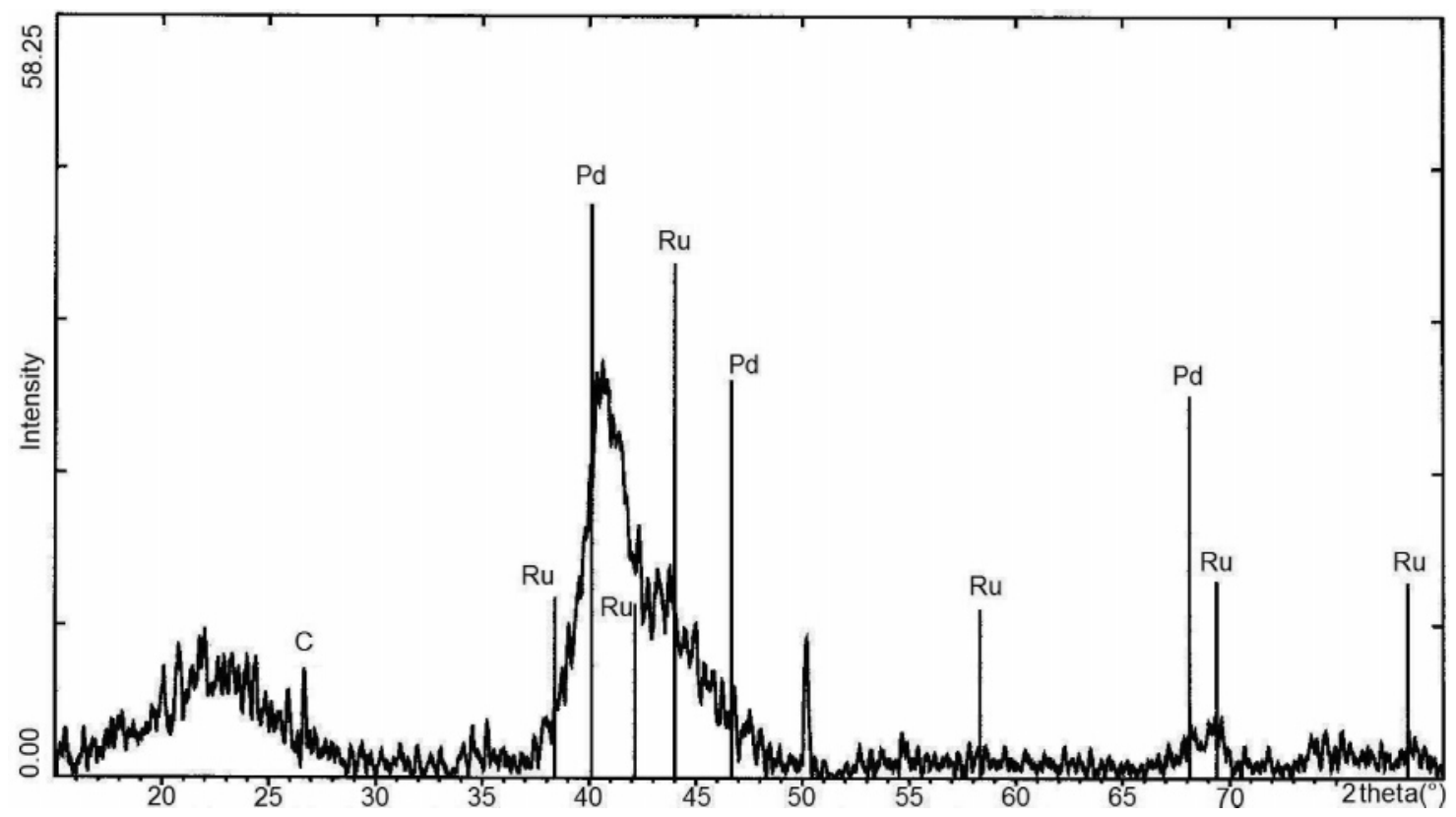

Figure 5. XRD pattern of the supported cluster $\left(\mathrm{NEt}_{4}\right)_{2}\left[\mathrm{Pd}_{6} \mathrm{Ru}_{6}(\mathrm{CO})_{24}\right](3)$ after thermal treatment.

adopted is that of $\mathrm{Ru}$. In the case of $\mathbf{3}$, a bimetallic phase is observed by XRD. However, ruthenium and palladium are nonmiscible on most of the compositional range according to the binary phase diagram, ${ }^{39}$ indicating that the use of clusters as precursors might have forced the formation of true bimetallic particles at the nanoscale. This is obviously of great importance for potential applications of these materials.

This study demonstrates the ability of the SIMS technique to provide detailed information on the samples that would otherwise be unavailable. First of all, it is demonstrated that there is no strong chemical interaction between the clusters and the support when they are simply brought into contact with each other in a mixture of solvents: clusters $\mathbf{1 - 3}$ are molecularly intact on the support at the end of the physisorption step. Second, the occurrence of cluster agglomeration in all cases is unambiguously deduced from the high-mass SIMS spectra, and confirmed by SEM. Third, the presence of the counterion in the case of $\mathbf{3}$, before, but not after, heating, is also shown clearly by SIMS, and corroborated by XPS. This is a very interesting result, considering that for the same cluster supported on the siliceous MCM-41, activated thermally, and used as an efficient hydrogenation catalyst, the fate of the counterion had never been determined. ${ }^{12}$ And finally, the loss of ligands during thermal treatment, leaving metallic particles (of varying sizes and shape) on the surface, is observed in all cases. This shows how SIMS allows us to get the molecular information that is needed at each step of the preparation of materials based on molecular precursors. The control on the size of the obtained supported particles could not be achieved in this study (given that the particles observed by SEM are up to $1 \mu \mathrm{m}$ in size rather than a few nanometers). This is most probably due to the lack of strong interaction between the precursors and the support, and is inherent to the use of carbonaceous materials, because their surface is inert as compared to inorganic oxides. However, a detailed picture of the sample could be obtained at various stages of its preparation, and a certain control over the composition of the supported phase was made possible owing to the use of mixed-metal clusters of known stoichiometry. This is a major advantage when the local structure rather than the bulk composition is of importance for possible applications.

\section{Conclusion}

It is shown that three mixed-metal clusters (two $\mathrm{Ru}-\mathrm{Pt}$ and one $\mathrm{Ru}-\mathrm{Pd}$ species) can be physisorbed in a molecularly intact fashion on the surface of a carbon support. The subsequent thermal activation allows them to lose their ligands and to form a supported bimetallic phase. This is assessed by a combination of physicochemical techniques, among which SIMS gives the clearest picture, thanks to the molecular information that can be retrieved from the spectra. Before activation, it is found that the molecular clusters are agglomerated on the support. After activation, the ligands and the counterion (if any) are lost and the formed metallic phase does not contain detectable fragments corresponding to single cluster cores, but both metals at least partially reduced.

Acknowledgment. We gratefully acknowledge financial support from the Belgian National Fund for Scientific Research (F.N.R.S.) and the "Communauté Française de Belgique" (through a Concerted Research Program, ARC). This work was also supported by the Interuniversity Attraction Pole program on "Quantum sized effects in nanostructured materials" of the Belgian Federal State. The ToF-SIMS equipment was acquired with the support of the Région Wallonne and FRFC-Loterie Nationale of Belgium. We also acknowledge B. F. G. Johnson and S. Wilkinson (University of Cambridge, U.K.) for providing the starting materials for the syntheses, E. Gaigneaux for access to XPS and XRD, R. Legras for access to SEM, NORIT for supplying the carbon support, and J.-F. Statsijns for technical support.

\section{References and Notes}

(1) Süss-Fink, G.; Meister, A.; Meister, G. Coord. Chem. Rev. 1995, 143,97

(2) Vargaftik, M. N.; Moiseev, I. I.; Kochubey, D. I.; Zamaraev, K. I. Faraday Discuss. 1991, 92, 13.

(3) Johnson, B. F. G.; Martin, C. M.; Schooler, P. Chem. Commun. 1998, 1239.

(4) Süss-Fink, G.; Meister, G. Adv. Organomet. Chem. 1993, 35, 41.

(5) Lewis, L. N. Chem. Rev. 1993, 93, 2693.

(6) Braunstein, P.; Rosé, J. In Comprehensive Organometallic Chemistry II; Adams, R. D., Ed.; Elsevier: U.K., 1995; Vol. 10, Chapter 7, pp $351-385$. 
(7) Puddephatt, R. J. In Metal Clusters in Chemistry; Braunstein, P., Oro, L. A., Raithby, P. R., Eds.; Wiley-VCH: Weinheim, 1999; Vol. 2, pp 605-615.

(8) Braunstein, P.; Rosé, J. In Metal Clusters in Chemistry; Braunstein, P., Oro, L. A., Raithby, P. R., Eds.; Wiley-VCH: Weinheim, 1999; Vol. 2, pp 616-677.

(9) Metal clusters in Catalysis; Gates, B. C., Guczi, L., Knözinger, H., Eds.; Studies in Surface Science and Catalysis; Elsevier: Amsterdam, 1986; Vol. 29.

(10) Muetterties, E. L. Science 1977, 196, 839

(11) Ichikawa, M. Adv. Catal. 1992, 38, 283.

(12) Raja, R.; Sankar, G.; Hermans, S.; Shephard, D. S.; Bromley, S.; Thomas, J. M.; Johnson, B. F. G.; Maschmeyer, T. Chem. Commun. 1999, 1571.

(13) Hermans, S.; Raja, R.; Thomas, J. M.; Johnson, B. F. G.; Sankar,

G.; Gleeson, D. Angew. Chem., Int. Ed. 2001, 40, 1211.

(14) Raja, R.; Khimyak, T.; Thomas, J. M.; Hermans, S.; Johnson, B.

F. G. Angew. Chem., Int. Ed. 2001, 40, 4638.

(15) Gladfelter, W. L.; Geoffroy, G. L. Adv. Organomet. Chem. 1980, $18,207$.

(16) Hermans, S.; Sloan, J.; Shephard, D. S.; Johnson, B. F. G.; Green,

M. L. H. Chem. Commun. 2002, 276.

(17) Hills, C. W.; Nashner, M. S.; Frenkel, A. I.; Shapley, J. R.; Nuzzo,

R. G. Langmuir 1999, 15, 690 .

(18) Nashner, M. S.; Frenkel, A. I.; Somerville, D.; Hills, C. W.; Shapley, J. R.; Nuzzo, R. G. J. Am. Chem. Soc. 1998, 120, 8093.

(19) Nashner, M. S.; Frenkel, A. I.; Adler, D. L.; Shapley, J. R.; Nuzzo, R. G. J. Am. Chem. Soc. 1997, 119, 7760.

(20) Xiao, F. S.; Ichikawa, M. J. Catal. 1994, 147, 578

(21) Diaz-Ayala, R.; Arroyo, L.; Raptis, R.; Cabrera, C. R. Langmuir 2004, 20, 8329.

(22) McNicol, B. D.; Rand, D. A. J.; Williams, K. R. J. Power Sources 1999, 83, 15 .

(23) Lefèvre, M.; Dodelet, J. P.; Bertrand, P. J. Phys. Chem. B 2000, $104,11238$.

(24) Bertrand, P.; Weng, L. T. Static mode secondary ion mass spectrometry; In Surface characterization, a user's sourcebook; Brune, D.,
Hellborg, R., Whitlow, H. J., Hunderi, O., Eds.; Scandinavian Scientific Publisher, Wiley-VCHP: Weinheim, 1997; pp 334-353.

(25) Delcorte, A. Fundamental aspects of organic SIMS. In ToFSIMS: Surface analysis by mass spectrometry; Vickerman, J. C., Briggs, D., Eds.; SurfaceSpectra/IMPublications: Manchester, 2001; pp 161-194.

(26) Johnson, B. F. G.; McIndoe, J. S. Coord. Chem. Rev. 2000, 200202, 901 .

(27) Aubriet, F.; Poleunis, C.; Bertrand, P. Appl. Surf. Sci. 2003, 203204, 114.

(28) Feld, H.; Leute, A.; Rading, D.; Benninghoven, A.; Henkel, G.; Kruger, T.; Krebs, B. Z. Naturforsch. (B) 1992, 47, 929.

(29) Chao, K. J.; Lin, L. H.; Yang, M. H. Catal. Lett. 1996, 38, 279.

(30) Hermans, S.; Khimyak, T.; Johnson, B. F. G. J. Chem. Soc., Dalton Trans. 2001, 3295.

(31) Brivio, E.; Ceriotti, A.; Della Pergola, R.; Garlaschelli, L.; Demartin, F.; Manassero, M.; Sansoni, M.; Zanello, P.; Laschi, F.; Heaton, B. T. J. Chem. Soc., Dalton Trans. 1994, 3237.

(32) Schueler, B. W. Microsc. Microanal. Microstruct. 1992, 3, 119.

(33) Delcorte, A.; Vanden Eynde, X.; Bertrand, P.; Reich, D. F. Int. J. Mass Spectrom. 1999, 189, 133.

(34) Delcorte, A.; Hermans, S.; Devillers, M.; Lourette, N.; Aubriet, F.; Muller, J.-F.; Bertrand, P. Appl. Surf. Sci. 2004, 231-232, 131.

(35) Delcorte, A.; Bertrand, P. Int. J. Mass Spectrom. 1999, 184, 217.

(36) Johnson, B. F. G.; Quadrelli, E. A.; Ferrand, V.; Bott, A. W. J. Chem. Soc., Dalton Trans. 2001, 1063.

(37) Rouxhet, P. G.; Genet, M. J. Chemical composition of the microbial cell surface by XPS. In Microbial cell surface analysis, structural and physicochemical methods; Mozes, N., Handley, P. S., Busscher, H. J., Rouxhet, P. G., Eds.; VCH Publishers: New York, 1991; pp 173-220.

(38) Miedema, A. R. Z. Metallk. 1978, 69, 287.

(39) Binary Alloy Phase Diagrams; Massalski, T. B., Ed.; American Society for Metals: Materials Park, OH, 1986.

(40) Bertrand, J. A.; Cotton, F. A.; Dollase, W. A. Inorg. Chem. 1963 2, 1166 . 